\title{
IMPRESSÕES DE ÁFRICA: O ESPAÇO MOÇAMBICANO EM A ÁRVORE DAS PALAVRAS, DE TEOLINDA GERSÃO
}

Silvana Maria Pantoja dos Santos (UEMA)

Thalita de Sousa Lucena (UEMA)

Resumo: O espaço literário tem importância fundamental para a compreensão dos fatos narrados. Sua relação com os outros elementos da narrativa tece marcas de vivências particulares e coletivas relevantes para a consolidação da memória. Le Goff (1996) afirma que a memória, por sua função psíquica, evoca informações e lembranças em lapsos temporais descontínuos. Para tanto, tais recordações dependem do lugar, motor que também se encarrega de contar e fazer histórias. A relação entre espaço e memória gera imagens singulares com significados simbólicos de sentimentos, sensações e valores que são construídos no texto literário. Sendo assim, esse trabalho objetiva analisar a representação dos espaços de memória na obra A Árvore das palavras, de Teolinda Gersão, procurando entender a relação que a personagem central estabelece com a cidade de Lourenço Marques, Moçambique e, de forma menos acentuada, com espaços portugueses, por meio do discurso memorialístico. A pesquisa tem como base teórica a visão de Bachelard (1993), Halbwachs (2006), dentre outros. A obra traz informações de vivências pós-coloniais, referências aos aspectos culturais, de memória histórica do lugar e ainda um nítido destaque ao espaço ficcional, construído a partir de segregações raciais numa perspectiva que representa a mentalidade do mundo colonial. Por meio dessa representação, o leitor percebe que a cidade não é concebida apenas como agregações populacionais ou demarcações geográficas: há representações simbólicas pautadas em sociabilidades, nas experiências e significados que emanam do cotidiano e trazem por suas manifestações de culturas e costumes, o imaginário social.

Palavras-chave: Literatura; Espaço; Memória; Moçambique.

Abstract: Literary space has fundamental importance for the understanding of facts narrated, its relationship with the other elements of the narrative produce a particular brand of experiences and collective experiences relevant to the memory consolidation. Le Goff 
(1996) says that the memory, in his psychic function, evokes information and memories in discontinuous time lapses. Therefore, these memories depend on the place that can be considered an engine responsible to tell and make histories. The relations between space and memory creates unique images with symbolic meanings of feelings, sensations and values that are constructed in the literary work. Thus, this work aims to analyze the space representation in the work "A Árvore das palavras", of TeolindaGersão, seeking to understand the relation that the central character has with the Lourenço Margues city, Moçambique and, someway less markedly, with Portuguese spaces, through memorialistic discourse. The research is based on theoretical space in the view of Bachelard (1993), Halbwachs (2006) among others. The work brings information from postcolonial experiences, references to cultural aspects, historical memory from the place and also a clear emphasis on the fictional space, built from racial segregation in a perspective that is the mentality of the colonial world. Through of this, the reader perceives that the city is not conceived only as population aggregations, or geographical demarcations: there are symbolic representations based on sociability, in the experiences and meanings that emerge from the daily life, and bring by their cultures manifestations and behaviors, the Social imaginary.

Keywords: Literature; Space; Memory; Moçambique.

\section{INTRODUÇÃO}

A produção literária de Teolinda Gersão envolve diferentes possibilidades de leitura, posto que está voltada para as relações humanas e fatos históricos, com ponderações de cunho social, fundamentais à sua dicção literária e reflexiva nas humanidades.

A autora portuguesa começou a publicar ficção aos 41 anos de idade, após o seu doutoramento. Recebeu o prêmio do romance e novela da Associação Portuguesa de Escritores 
(1995) com a obra A casa da cabeça de cavalo, além do prêmio Máximo de Literatura (2008) pela obra $A$ mulher que prendeu a chuva, dentre outros. Publicado em 1997 em Portugal, $A$ árvore das palavras é o seu primeiro livro a chegar oficialmente no Brasil, em 2004.

A árvore das palavras é um romance ambientado em Lourenço Marques, atualmente Maputo, capital de Moçambique, no período histórico de guerras coloniais. As sucessivas independências no continente africano nos anos de 1950 levaram Angola, Moçambique e Guiné ao anseio por liberdade. A substância dessa obra também demonstra esse desejo.

Assim, este artigo propõe-se analisar em $A$ árvore das palavras a relação do sujeito com os espaços de convivência com a/na cidade, a partir das impressões de Gita, protagonista da narrativa. A obra retrata os conflitos, anseios e frustrações dos habitantes do lugar por meio das impressões da narradora. Trata-se de uma narrativa de escrita memorialística, cujas marcas individuais e também coletivas evidenciam os costumes e o cotidiano dos colonos, especialmente das mulheres.

O enredo circula em torno de um mosaico narrativo no qual as testemunhas da trama alternam-se a partir de três 
partes que se edificam na obra. Na primeira, a menina Gita dá luz ao mundo e às coisas a partir de impressões formuladas por meio do olhar receptivo de criança, que prossegue palmilhando o seu entorno e os demais espaços que ambientam a obra.

A segunda parte é conduzida pela voz de Amélia, mãe de Gita, que expõe frustrações e problemas íntimos: os âmagos da infância em Lisboa e a saída para Lourenço Marques em busca de melhores condições de vida. Sem criar raízes com a família e com a terra africana, a personagem parte para Sidney, na Austrália, abandonando a antiga cidade, o esposo e a filha para viver com Bob Pereira, um homem de posses com quem se comunicava por cartas e que pouco conhecia.

A identidade portuguesa é muito forte em Amélia, de modo que a personagem incorpora aversão e repugnância ao lugar africano. "É preciso cuidado, dizia Amélia. Estar atento. Tudo parece bem à superfície, mas a cidade está podre e cheia de contágios" (GERSÃO, 2004, p.10-11). Tais impressões não se referem apenas ao lugar, mas também aos seus habitantes. Na sua condição de estrangeira, Amélia trava um olhar branco, racista, em relação ao negro:

Mas é inútil falar destas coisas com Amélia, que insiste na conviç̧ão de que os loiros estão no ponto mais alto 
da hierarquia das raças e de que os escuros portugueses estão no fundo da escala, logo a seguir a indianos e negros. (GERSÃO, 2004, p.53)

Na terceira parte, Gita está com seus dezessete anos. Sua relação com o mundo já se dá de forma reflexiva, com consciência dos problemas sociais. A compreensão de que "há coisas para mudar em África", envolvendo o ódio dos brancos para com os negros, o tratamento dado à mulher, considerada "burro de puxar carroça". (GERSÃO, 2004, p.162), evidenciam que a personagem compartilha das dores da colônia Moçambicana.

No interior do romance, travam-se conflitos demarcados por inúmeros problemas sociais, raciais e econômicos que constroem retratos refletidos nas vivências cotidianas.

O registro narrativo revela identidades circundadas por sentimentos, imagens, percepções e comportamentos que fixam o fazer literário como fonte produtiva para os estudos de representações culturais. Tal processo circunscrevese a partir das envergaduras da realidade social, atada a condições históricas e políticas que tecem memórias na escrita literária. Assim, essa arte dialoga com a sociedade por meio do recurso da representação, associando diversas leituras de mundo e conteúdos por repetições e criações. 
Como declara Roberto Machado, "a linguagem literária é uma linguagem que se reduplica, se repete, se desdobra indefinidamente, fazendo-se espelho, imagem de si própria" (2005, p.114).

O espaço literário, enquanto elemento da narrativa, recebe atenção especial por ser um dos articuladores do enredo. Vinculado aos demais elementos da trama, o espaço dá testemunho de acontecimentos que perduram no imaginário social. Como garante Osman Lins $^{1}$, o espaço é imprescindível ao registro literário, uma vez que "tudo na ficção sugere a sua existência - e mesmo a reflexão, oriunda de uma presença sem nome, evoca o espaço onde a proferem e exige um mundo no qual recobra sentido" (1976, p.70).

\section{OS ESPAÇOS DE INTIMIDADE E OS AFETOS DEPOSITADOS}

O detalhamento do espaço em $A$ árvore das palavras é expresso com maior vigor por meio das impressões de Gita, personagem ativa que vai dando visibilidade às coisas em seu entorno. Sua visão modela o espaço que vai assomandose à proporção que se adentra a narrativa. Há uma simbiose entre ambos - personagem e espaço - acentuada por uma carga de magnetismo numa relação recíproca.

1 Trata-se de um importante estudo sobre o espaço na obra de Lima Barreto, cujo trabalho tem embasado pesquisas sobre o espaço na narrativa literária de muitos estudiosos, como Luís Alberto Brandão Santos, Ozires Borges Filhos, dentre outros. A edição usada justifica-se pela ausência de outras mais atuais. 
A casa de Gita é demarcada por dois territórios: "e logo ali a casa se dividia em duas, a Casa Branca e a Casa Preta. A Casa Branca era de Amélia, a Casa Preta a de Lóia. O quintal era em redor da Casa Preta" (GERSÃO, 2004, p.10), demarcação que remete à seguinte simbologia: Amélia - mãe branca e Lóia - ama de leite negra. Desse modo, a divisão dos espaços envolve dois mundos demarcados por valores axiológicos que representam a segregação racial. Lourenço Marques também é representado na bipolaridade.

Uma parte da cidade para brancos, outra para negros, hotéis e restaurantes para brancos, hotéis e restaurantes para negros, machimbombos para brancos e machimbombos para negros - não era só isso, mas nas pequenas coisas se apartavam. Assim por exemplo os bancos de jardins e de ruas tinham letreiros pregados: "brancos" e "não brancos", [...] e se, por exemplo, brancos e negros fossem andar nos mesmos passeios, os negros tinham de sair dele, para dar lugar aos brancos. (GERSÃO, 2004, p.67-68)

A segregação se dá a partir da presença do colonizador português, sendo a cidade de "Caniço" o lugar de pertencimento dos nativos: "o outro lado existia para servir este, levantando em frente ao mar [...]. O outro lado, por teimar em se embrenhar no novelo do 'Caniço', perdia sempre, em dada altura, a geometria" (GERSÃO, 2004, p.82-83). 
Borges Filho (2007) entende que a polarização de perspectivas espaciais acarreta valores que são atribuídos por suas circunstâncias sociais, que perpassam desdobramentos de vivências, tais correlações modelam comportamentos.

Para Lins (1976), os espaços sociais são demarcados por estilos de vida e pelos quadros que realçam cenas cotidianas e relacionamentos humanos.

O quintal é o primeiro espaço articulador de sua percepção. Esse é, sobretudo, um dos nichos de vivência de maior destaque na obra, desenhado como uma espécie de fronteira.Vale destacar que nesse sistema de oposições binárias, a personagem Gita deixa claro que essa cisão também está na consciência da representação dos espaços:

O quintal crescia como uma coisa selvagem. [...] E Amélia diria franzindo a testa: O jardim tornou-se um matagal. E fecharia com força a janela. Mas não era um jardim, era um quintal selvagem, que assim se amava ou odiava, sem meio termo, porque não se podia competir com ele. Estava lá e cercava-nos e ou se era parte dele, ou se não era. Ou não queria ser. Por isso não insistia de o domesticar. Quero isso varrido, dizia ela à Lóia. Nenhuma casca de fruta podia ser abandonada, nenhum caroço deitado ao chão. Isso é lá no "Caniço", insistia, sempre que queria repudiar qualquer coisa. Aqui não. (GERSÃO, 2004, p.10 grifo nosso) 
Considerando a subjetivação de Amélia, não seria possível haver beleza em um lugar "selvagem", logo o que crescia no quintal deveria ser banido. Em contrapartida, pela percepção de Gita, vê-se que ela faz alusão à natureza e à beleza dos objetos, movimentos e corpos que constituem um paraíso em harmonia: do quintal emana uma espécie de êxtase, contentamento e prazer. Dele vem uma força de atração maior:

Corria-se em direção ao quintal, como se fosse sugado pela luz, cambaleavase transpondo a porta, porque se ficava cego por instantes, apenas o cheiro e o calor nos guiavam, nos primeiros passos, - o cheiro a terra, a erva, a fruta demasiado madura - chegando até nós no vento morno, como um bafo de animal vivo. (GERSÃO, 2004, p.9)

A luminosidade do quintal repercute na personagem, de modo que sua percepção não equivale apenas à distinção e à localização das coisas, mas remete a perspectivas subjetivas, a partir de gradientes sensoriais: luz, cheiro e sensações térmicas.

Por gradientes sensoriais, entendemse os sentidos humanos: visão, audição, olfato, tato, paladar. O ser humano se relaciona com o espaço circundante através de seus sentidos. Cada um deles estabelece uma relação de distância proximidade com o espaço. (BORGES FILHO, 2007, p.69) 
Assim, por meio da interferência de sentidos é possível detectar certas distâncias ou proximidades. Ademais, as impressões sensoriais vão ao encontro dos sujeitos por meio dos diferentes estímulos possíveis de acionar lembranças reconfortantes.

O mato. Mergulhava-se nele como no mar. E ele envolvia-nos com sua presença obsessiva - havia de tudo no mato, répteis, pássaros, antílopes, insectos, manchas de vegetação e longos troços desolados. Mas mesmo esses espaços aparentemente vazios eram densos, a vida cercava-nos, no arrulhar da rola, no grito rouco do sapo - boi, no canto enlouquecido da cigarra. [...] Fechávamos os olhos, sabendo que éramos a presa, e que uma força pesava sobre nós, como um encanto. (GERSÃO, 2004, p.50)

A percepção do espaço, somada às sensações visuais, olfativas, auditivas e térmicas refletem-se no modo como a personagem o descreve, bem como na influência que o espaço exerce sobre ela: as imagens em harmonia, a terra, os cheiros misturam-se a memórias particulares que se erigem pelos afetos construídos e travados entre espaço/personagem. Assim, as lembranças reconfortantes que se abrem aos órgãos dos sentidos provocam movimento no corpo que perduram no ser.

A percepção é consequência das experiências dos sujeitos frente à realidade na qual se inserem. De acordo com Santos 
(2015), o olhar é depositado sobre aquilo que seduz ou inquieta, não é apenas um mero objeto visualizado pelas retinas. Assim, é notório que o espaço do quintal possua dimensão valorada a partir da sensibilidade de Gita.

Considerando as múltiplas possibilidades de sentido, veem-se relações intrínsecas entre percepção e espaço. Embora haja uma "rápida cegueira" de Gita por causa da claridade demasiada do sol, a personagem continua a ser conduzida pelo cheiro, não acarretando responsabilidade perceptiva apenas à visão, tanto que Gita frisa em dado momento: "mas, como eu disse, não se precisava de olhos para ver, porque mesmo de olhos fechados se via" (GERSÃO, 2004, p.10).

Quanto ao valor de intimidade e pertencimento, Gita toma como propriedade o mato, o caniço, a casa preta, uma vez que a personagem demonstra afeto por esses espaços, o que Bachelard (1993) denomina de espaços topofílicos. A menina tem sangue português, mas ela abraça o mundo negro.

Gita tem a preocupação em disseminar costumes e crenças da sociedade africana: o cantar e dançar em volta das árvores, o direito de não se entregar à rotina, os percursos cotidianos e ainda faz uma crítica à realidade do sistema colonizador/colonizado do Mundo Moçambicano. 
O segmento social da cidade traz o prisma racial e cultural, comum à consciência dos habitantes do solo africano: brancos, negros, estrangeiros e mestiços; como agravante as múltiplas identidades curvam-se a um dominador: o discurso colonial que exerce sobre os indivíduos.

\section{DO QUINTAL À CIDADE MOÇAMBICANA}

A árvore das palavras traz outros ângulos de visões. À medida que Gita passa a transitar por outros espaços para além da casa, vai conhecendo melhor o mundo de Lóia.

Caminhamos perto de casas de pescadores - são de madeira, construídas sobre estacas, porque antigamente o terreno alagava. Estão pintadas de várias cores, predomina o azul, o branco, e um rosa avermelhado, a pintura começa junto ao chão, mistura-se com o pó do caminho. Algumas têm uma espécie de alpendre ou de sacada, porque uma parte do telhado avança, também seguro por estacas. (GERSÃO, 2004, p.139-140)

A percepção da personagem é direcionada para o colorido das casas e para as estruturas frágeis que as diferenciam das casas dos portugueses. A cidade de "Caniço" onde habitam os moçambicanos é decadente, apresenta problemas de infraestrutura, cuja fragilidade remete ao abandono do lugar. 
O cuidado em gerir nomes de espaços referenciais também demonstra que a narradora tem a preocupação em conservar o caráter histórico da cidade, uma vez que esses elementos citadinos trazem a perpetuação da presença humana por seus nomes, como bem se vê no excerto a seguir: "isso antes de Mário comprar a vanete em segunda mão na Rua do Trabalho e passarmos a ir mais vezes à Namaacha, a Vila Luísa, ao Bilene, à Porta Mahone ou ao Umbelúzi [...]" (GERSÃO, 2004, p.34).

Tais espaços com seu conjunto de referências integram valores simbólicos por permitir muito mais do que via de acesso e relações de trocas econômicas: existem vínculos afetivos interligados às vivências, imagens e juízos que transformam tais lugares em bens pessoais a partir da memória do lugar.

Toda a cidade, antes mesmo de constituir-se como aglomerado humano e suas características peculiares, como território de dominação-apropriação e desdobramentos de vivências individuais e coletivas, constitui-se como um embrião de trabalho, moradia, espaço de história, memórias e deslocamentos a partir dos registros de vida social.

A representação do urbano na produção ficcional de Teolinda Gersão é composta pela carnadura dos espaços 
por onde Gita circula, sendo uma conjuntura de lugares que integram a memória de Lourenço Marques: A Camtebe e a praia da Polama, onde se faziam piqueniques, o Hotel Polama e as recordações de Acelino, os barracos do Caniço, o calor e o acolhimento do solo africano: "África - tinha certeza - era o mais belo dos continentes" (GERSÃO, 2004, p.72).

Há momentos em que a cidade é descrita como extensão do lar, trazendo laços afetivos de acolhimento: "a cidade cerca-nos com seus muitos braços, os seus muitos círculos, nenhum dos quais nos exclui. Ninguém pode nos tirar essa sensação de pertencer, de estar contido" (GERSÃO, 2004, p.43-44); em outros, a cidade surge em uma perspectiva contrária: com um caráter indomável, desordenado, indomesticável que, aos olhos da narradora, é expresso como lado fatigante de África, bem como o seu poder entorpecente de sugar as forças de seus habitantes por meio de doenças, sofrimento, injustiças, misérias e tantas causas que configuram os contrastes da realidade social.

Vê-se que no descrever da cidade, a personagem Gita Ihe atribui vitalidade, partilhando com o leitor sensações diversas provocadas pelo espaço urbano, conferindo-lhe, em alguns momentos, atribuições que o transformam também em personagem. O descrever eminentemente 
subjetivo da narradora outorga a Lourenço Marques um envolvimento íntimo, sensação de complemento. Também se refere à natureza selvagem do solo africano, que a fascina de igual modo.

Quanto à atmosfera da obra, recorre-se à compreensão de Lins (1976). A atmosfera é um dos procedimentos literários que intenciona caracterizar o estado de espírito das personagens:

[...] consiste em algo que envolve ou penetra de maneira sutil as personagens, mas não decorre necessariamente do espaço, embora surja com frequência como emanação deste elemento, havendo casos em que o espaço justificase exatamente pela atmosfera que provoca. (LINS, 1976, p.76)

Tem-se a atmosfera como uma sensibilidade que emana do espaço, externando sensações de alegria, tristeza, angústia, suspense, violência, dentre tantas outras. É valido esclarecer que a mesma apresenta um caráter abstrato, uma vez que é possível apreendê-la nas entrelinhas do texto, como se percebe no trecho em destaque:

As coisas ganham limite e solidez, brilho e cor, e eu caminho dançando por entre elas. As árvores dançam, as folhas dançam, a chuva dança, o sol e a lua dançam. Tudo o que há a fazer é deixasse puxar para dentro do seu 
círculo, deixar-se puxar sem medo para dentro da órbita desmesurada das coisas. (GERSÃO, 2004, p.24-25)

Há uma adjetivação positiva que envolve a personagem e todo o seu entorno. Os indícios de harmonizações criados pela narradora emanam uma atmosfera de tranquilidade, ventura e gozo, em um dia agradável de céu azul e brisa que passa por seu espírito e permite que a mesma encontre a beleza da vida nesse momento. É interessante notar que a pontuação desse tom deleitável perpassa também o sujeito leitor, como se ele também estivesse passando por tais experiências.

A relação de Gita com o espaço urbano tem uma perspectiva díspar em relação à Amélia, há contrastes de juízo de valor, concepções, divergências nos posicionamentos sobre os conflitos coloniais de Lourenço Marques, bem como há construções identitárias que trazem na obra peculiaridades da memória coletiva e da memória individual. E sobre esses tipos de memórias, Maurice Halbwachs (2006) assevera que a primeira é determinada pelas vivências particulares; e a segunda pode ser entendida através das impressões particularizadas das experiências de um grupo. Sendo assim, é válido dizer que o discurso histórico dentro da ficção faz referência a um processo coletivo inserido num determinado contexto social. 
A obra $A$ árvore das palavras reporta-se aos momentos em que Moçambique encontra-se no auge da luta pela independência. Pelo romance, tem-se a representação da rememoração dos fatos com a carga emotiva que não se encontra na explicação pura e objetiva da história. Nesse viés, compreende-se que Gita se integra ao lugar, aos modos de pensamento e as experiências comuns ao grupo, sendo então testemunha, por sua consciência individual, acerca da vida social. De quando em quando, denuncia a relação tensa da metrópole portuguesa com terra moçambicana, sempre reforçando a falta de diálogo entre ambas:

Então, de repente, rebentou a guerra. Como um terreno minado explodindo. Não foi para ninguém uma surpresa, sabia-se que iria acontecer, já tinha acontecido noutros lugares, mais tarde ou mais cedo ia chegar aqui. Portugal era um pais mal governado. Mal pensado. (GERSÃO, 2004, p.63)

O país colonizador imprime repressões políticas, econômicas e sociais sobre o mundo colonizado. A dominação e exploração do solo africano distanciam muito mais a relação de Gita com o mundo português, uma vez que ela se coloca como porta-voz dos silenciados da sociedade moçambicana e entende-se como subjugada pela metrópole que lhe nega emancipação, por isso traz seu discurso vinculado ao desejo 
veiculado por cartazes com letras legíveis: "viva Moçambique independente" (GERSÃO, 2004 p.164).

Quando Gita resolve partir, o seu sofrimento é notório: "um mundo que fica para trás. Rios, machambas, savanas, palmares, os grandes espaços, os largos horizontes, e uma árvore que crescia nos sonhos e chegava ao céu - que sabem eles disso, que podem eles compreender?" (GERSÃO, 2004, p.188). Nesse questionamento jogado ao ar, Gita evidencia sua lealdade para com o lugar: a dúvida da narradorapersonagem quanto à compreensão do espaço sobre sua partida revela que a mesma lhe confere posição privilegiada.

Apesar de Lourenço Marques receber o apreço de Gita, a protagonista não deixa de revelar as cicatrizes causadas pela relação com o Ocidente. O afeto entre África e alguns descendentes do país colonizador, como é o caso de Gita, transcende a tudo. Isso fica evidente no modo como a personagem se despede da cidade e do seu pai, com a queixa de que vai lhe faltar o fôlego na capital Portuguesa.

\section{CONSIDERAÇÕES FINAIS}

Pelas discussões em torno da relação que o sujeito estabelece com os espaços de memória da cidade em $A$ árvore das palavras, vê-se que há respostas variadas no tocante às conexões dos sujeitos com os lugares de vivências, aferidas 
pelo calor das lembranças, que mesmo no plano particular, permitem uma compreensão do olhar do outro.

Nesse sentido, as reminiscências da protagonista permitem pensar o processo de identificação do sujeito para com o lugar. A personagem Lourenço Marques que se materializa no espaço do texto literário se corporifica como extensão do lar de Gita, como também representa a mãe África, pelos costumes, crenças e seus mistérios, que se coadunam ao plano real pelo caráter verossímil da literatura.

Quanto ao apego aterra, ao lar, os espaços de recordações do quintal, da Casa Branca, da Casa Preta, do Caniço, do Mato e de tantos espaços tipicamente africanos se fazem presentes nas impressões de Gita. Isso corrobora com o pensamento de Bachelard (1993) ao afirmar que os espaços de convivência recebem dimensão valorada, quase humana, por acompanhar os ciclos da vida de seus sujeitos.

A personagem imprimevalor ao seu ambiente multicultural, a partir de lembranças da infância e da adolescência. Por essa consciência do passado, o sentimento pelo lugar tem caráter dominante. Vê-se ainda que as recordações e descobertas dos primeiros anos estão presas a cheiros, ruídos e asperezas que ressoam de modo proeminente, de forma que a Casa e o Quintal passam a ter maior visibilidade 
do que os demais espaços urbanos. A afeição de Gita pelos microespaços demonstra que a mesma toma essa unidade por condizer à sua condição: é uma figura nata que confia sua vida emocional ao lar e aos lugares africanos que comportam sua identidade.

Os espaços urbanos avivados pelas impressões da protagonista vinculam-se também à memória do lugar nos encontros à tardinha na Catembe, nos concertos no Jardim Vasco da Gama, nos trajetos por espaços segregados e nas grandes avenidas, que comportam as relações sociais, a partir da herança cultural que os envolve.

\section{REFERÊNCIAS}

BACHELARD, Gaston (1993). A poética do espaço. São Paulo: Martins Fontes.

BORGES FILHO, Ozires (2007). Espaço e Literatura: Introdução à Topoanálise. São Paulo: Ribeirão Gráfica e editora.

GERSÃO, Teolinda (2004). A árvore das Palavras. São Paulo: Planeta.

MACHADO, Roberto (2005). Foucault, a filosofia e literatura. 3.ed. Rio de Janeiro: Jorge Zahar.

HALBWACHS, Maurice (2006). A memória coletiva. Trad. Beatriz Sidou. Centauro.

LINS, Osman (1978). Espaço romanesco de Lima Barreto. São Paulo: Editora Ática.

SANTOS, Silvana Maria Pantoja dos (2015). Literatura e memória entre os labirintos da cidade: representações na poética de Ferreira Gullar e H. Dobal. São Luís: Editora UEMA. 
Silvana Maria Pantoja dos Santos é Doutora em Teoria Literária. Prof.a dos Programas de Pós-Graduação em Letras - Mestrado, da UEM, da UEMA e da UEP - UESPI. Atua na Linha de Pesquisa Literatura, memória e cultura.

Thalita de Sousa Lucena é Mestranda em Teoria Literária pelo Programa de Pós-Graduação em Letras da UEMA. Integrante do Grupo de Pesquisa Interdisciplinar em Literatura e Linguagem - LITERLI da UEMA.

Recebido em 16 de março de 2017. Aprovado em 10 de abril de 2017. 